УДК 902/904

https://doi.org/10.24852/2587-6112.2021.3.19.23

\title{
О МАЛЫХ БУЛГАРСКИХ ГОРОДАХ ${ }^{1}$
}

\author{
(c) 2021 г. А.М. Губайдуллин
}

В статье рассматривается тема изучения «малых городов» Волжской Булгарии, которые являлись важным элементом в процессе феодализации и экономической жизни любого государства в Средние века. Здесь автор обращает внимание на историю исследования вопроса и методы его решения. Особое внимание уделяется рассмотрению площадей булгарских городищ, что является немаловажным при выделении этой категории укрепленных поселений из общей массы таких булгарских памятников. Несомненно, что только один размер поселения внутри оборонительных линий не может быть единственным показателем социального статуса. Необходимо учитывать и площади примыкавших посадов, мощность их культурного слоя, а также характер и количество археологического материала.

Ключевые слова: археология, Средние века, Волжская Булгария, городища, малые города.

\section{SMALL BOLGAR TOWNS 2}

\section{A.M. Gubaidullin}

The paper addresses the study of "small towns" of Volga Bolgaria, which were an important element in the feudalization process and the economic life of any state in the Middle Ages. The author draws attention to the history of the study of the issue and methods of its resolution. Particular attention is drawn to the areas of Bolgar fortified settlements, which is important in distinguishing this category of fortified settlements from the overall number of such Bolgar monuments. There is no doubt that the settlement's size within the defensive lines alone cannot be the only indicator of social status. One should take into account the area of the adjoining suburbs, the thickness of their cultural layer, as well as the nature and amount of archaeological material.

Keywords: archaeology, Middle Ages, Volga Bolgaria, fortified settlements, small towns.

Изучение процесса становления и развития городов Волжской Булгарии входит в число значимых задач булгарской археологии. На сегодняшний день имеются общие представления о городах Среднего Поволжья X-XIV вв. как центрах ремесла, торговли, которые имели административно-хозяйственные, военные и культурные функции. В то же время в последние десятилетия XX в. и начале XXI в. были достигнуты значительные успехи в области археологического изучения булгарских укрепленных поселений домонгольского и золотоордынского периодов. Нужно признать, что некоторые аспекты “городской” проблематики в археологии Волжской Булгарии не нашли еще удовлетворительного решения. Например, среди исследователей не сложилось единого мнения о конкретных признаках, выделяющих города из общей массы укрепленных поселений. Достаточно важным является выяснение роли городов в процессе феодализации различных государств Средневековья, а также выявление их социального облика. В связи с этим интересно рассмотреть вопрос о выделении категории т. н. «малых городов». Исследователи уже не раз обращались к этой теме. Необходимо отметить основательную работу А.В. Кузы, посвященную попытке выделения малых городов среди населенных пунктов Древней Руси X-XIII вв. (Куза, 1989). В ней скрупулезно рассмотрены имеющиеся источники по данной теме, и в первую очередь обращается внимание на данные археологии. Исследователь указывал, что его цель: «... разработать шкалу археологически уловимых критериев для определения облика поселения и с ее помощью выявить малые города» (Куза, 1989, с. 13). Нужно констатировать, что А.В. Куза наиболее близко приблизился к пониманию такого важного вопроса. К попытке решения этой темы обращались и другие исследователи. Например, В.Ю. Коваль также попытался выявить основные отличительные особенности малых городов средневековой Руси (Коваль, 2014, с. 76-79). Исследователями отмечалась и слабая археологическая изученность этой категории поселений, дела-

\footnotetext{
Работа выполнена при поддержке гранта РФФИ 18-09-40114 Древности «Страна городов» - комплексное изучение городищ Волжской Булгарии современными методами.

2 The work was supported by the RFBR grant 18-09-40114 "Country of Cities" Antiquities - a Comprehensive Study of the Fortified Settlements of Volga Bolgaria by Modern Methods
} 
лись попытки решить данный вопрос и для позднего Средневековья (Гордеев, Павленко, 2004). Нужно отметить, что изучение древнерусских городищ проводилось более широко, чем поселенческих памятников Волжской Булгарии. Таким образом, для Древней Руси имеется большее количество археологических данных, позволяющих делать какиелибо серьезные предположения и выводы. На территории же Среднего Поволжья внимание оказывалось в основном крупным булгарским городищам, тогда как основная масса укрепленных поселений исследовалась разведочно или небольшими площадями, что сказывается на количестве археологического материала.

Одним из критериев выделения из большого количества городищ Волжской Булгарии т. н. «малых городов» есть немаловажный - укрепленная площадь, занимаемая памятником, а также размеры прилегающей части - посада, характер и количество находок, сделанных в ходе археологических разведок и раскопок. Поиски ответа на этот вопрос логически приводят к формально-типологической классификации городищ. Первый опыт в этом направлении был предпринят Н.Ф. Калининым в 50-х гг. XX в. Проработав материалы около трех десятков обследованных им булгарских городищ, Н.Ф. Калинин предложил классификацию памятников, в основу которой были положены размеры укрепленной территории поселений с учетом особенностей планировки, рельефа местности и характера культурного слоя (Калинин, Халиков, 1954, с. 63). Уже 60-70-е гг. XX в. ознаменовались выявлением новых многочисленных булгарских поселений, в том числе и городищ, вошедших в известный свод археологических памятников, составленный Р.Г. Фахрутдиновым (Фахрутдинов, 1975). Созданная им типология (Фахрутдинов, 1990), однако, принципиально не отличалась от калининской и не учитывала многие существенные признаки изучаемых памятников.

На самом деле, очень сложным является процесс по определению социального облика городищ. Здесь нужно учитывать множество факторов, где размеры укрепленной территории поселений играют, как нам кажется, первостепенную роль при их классификации. Бесспорно, только этот отдельно взятый признак не может служить достаточно надежным критерием оценки, т. к. кроме укрепленной части поселения часто имели и неукрепленные посады-пригороды. Необходимо также учитывать совокупность и харак- тер археологического материала, выявленного в результате раскопок. Исследователямиархеологами выделена целая группа признаков, которые могут характеризовать категорию т. н. «малых» и «больших» городов (Куза, 1989; Коваль, 2014, с. 76-79).

В разное время количество булгарских городищ в научных трудах указывалось неодинаково. Например, А.Х. Халиков доводил их число до 200 (Халиков, 1989, с. 90). Р.Г. Фахрутдинов включил в свою таблицу сведения о 161 памятнике (Фахрутдинов, 1990, с. 71-78). Ф.Ш. Хузин оперировал материалами 190 городищ (Хузин, 1993, с. 12-13), прибавляя к общему списку Р.Г. Фахрутдинова количество укрепленных поселений обулгаризированных буртас в Пензенской области, известных по работам Г.Н. Белорыбкина (Белорыбкин, 1985, с. 112). Здесь нужно заметить, что некоторые памятники вошли в свод Р.Г. Фахрутдинова ошибочно. Например, обваловка леса, проведенная в XIX столетии, была принята за городище, получившее в литературе название «Кильдюшевское» (Фахрутдинов, 1975, с. 178). Это же относится, например, и к т. н. «Ржавецкому городищу», предположительно датируемому ранним железным веком (Археологическая карта Татарской АССР. Западное Закамье, 1986, с. 39, № 200). Необходимо отметить - не все, что обнесено валом и рвом (или только рвом), можно отнести к остаткам укрепленных поселений. Характерным признаком таких объектов является незначительная мощность земляных сооружений. Вообще, ограда подобного типа в садово-парковом искусстве получила название «ax-ax (ah-ah)» или по-другому «волчий скок» (Плужников, 1995, с. 20). Этот довольно поздний термин происходит из Великобритании и представляет собой несколько разных типов, в том числе и обваловку определенной территории: участка леса, парка, сада и др. В свою очередь, натурное обследование местоположения так называемых «Шонгутского», «Сатламышевского» и «Тангачинского» городищ показало, что там никогда не было оборонительных сооружений, не найдено и материалов булгарского времени, т. е. сведения о памятниках строились на основе неточных данных. В связи с этим их следует исключить из списка укрепленных поселений. Существует и другой пример - наземное обследование и анализ аэрофотоснимков Балынгузского и Горкинского II городищ, считавшихся отдельными памятниками, показали, что это единый объект, искусственно разделенный исследователями. Его структура в планигра- 
фии и фортификации является цельной и не позволяет вычленить особенности планировки, способствующие обособлению какихто частей или участков. С другой стороны, в последние десятилетия были открыты совершенно новые памятники, неизвестные ранее: например, Исаковское городище (Губайдуллин, Измайлов, 1991, с. 109; Хузин, Измайлов, 1991, c. 152).

Учитывая вышесказанное, а также исключая памятники с неопределенной площадью, в целях нашего исследования можно оперировать данными по 187 городищам, подавляющее большинство которых хронологически относится к домонгольскому времени. Мы попытались более внимательно рассмотреть все имеющиеся в наличии показатели. Они распределяются на шесть отдельных групп, в каждой из которых размеры площадей тяготеют друг к другу: до 2 га, до 6 га, до 11 га, до 20 га, до 50 га и более 50 га. Таким образом, наблюдаются явные разрывы между группами. Так, наибольшее количество городищ находится в первой и второй группах -83 и 61 памятник соответственно. Затем идет резкое уменьшение числа укрепленных поселений: третья группа включает в себя 13, четвертая 7 и пятая - 10 городищ. Лишь шестая группа, в которую входят 13 памятников, вновь возрастает. Нами были условно разделены булгарские укрепленные поселения на три основные группы, и мы попытались интерпретировать каждую из них.

Вряд ли будет вызывать сомнение отнесение большинства городищ площадью до 6 га к феодальным усадьбам-замкам, которые составляли наиболее многочисленные укрепленные поселения в Средние века. К ним относится 144 городища. Однако, наряду с памятниками с небольшими примыкающими селищами, в данную группу входят и городища с обширными посадами и остатками интенсивной торгово-ремесленной деятельности. Последние из них, по нашему мнению, можно отнести к категории т. н. «малых» городов, являющихся центрами небольших округов и несших определенные административно-хозяйственные функции. Ю.А. Зеленеев, например, их относит к периферийным городам, которые были «естественным элементом социально-экономического и политического развития булгарского государства, частью урбанизационного процесса», в то же время их роль в политической и экономической структуре страны могла изменяться с течением времени (Зеленеев, 2013, с. 59).
Следующая группа памятников с укрепленной площадью от 6 до 50 га условно отнесена нами к средним по размерам городам. Их общая численность достигает 30. Социальная интерпретация их довольно сложна, так как одни могли быть столицами отдельных княжеств, другие - административными центрами больших областей. Эту группу, конечно, можно было бы отнести также к «малым» городам, как было сделано А.В. Кузой по отношению к Древней Руси (Куза, 1989 , с. 11), но наблюдаются слишком большие отличия в количественном соотношении с первой группой. Выделяются 13 городищ, чья укрепленная площадь превышает 50 га. Скорее всего, большинство из этих памятников являлись центрами крупнейших земелькняжеств, а «Великий город» - Биляр, 620 га (с учетом посадов - более 800 га), был политическим, административно-хозяйственным, духовным центром всего Булгарского государства в домонгольский период.

Мы сознательно не рассматриваем возможность существования в исследуемый период времени категории крепостей, т. е. памятников, несших только охранно-дозорные функции, которые располагались вдоль границ государства или отдельных административно-хозяйственных территорий. Это исходит из того, что в развитое Средневековье крепости как элементы обороны прекращают свое существование и появляются вновь только в Новое время. Довольно часто в научной литературе встречается отнесение некоторых городищ к крепостям, которое не имеет никаких доказательств. Обычно приводятся лишь субъективные мнения, основанные на личных умозаключениях авторов. Только иногда в качестве довода выделения данной категории памятников служит аргумент об отсутствии (в наше время) культурного слоя (а также археологических находок) на некоторых укрепленных поселениях или же незначительная его мощность. Однако это не может являться доказательством, т. к. в течение нескольких веков культурный слой подвергался плоскостному смыву, что особенно характерно для мысовых городищ или городищ, примыкающих к краям террас. И чем больше их крутизна, тем больше объем смыва. Причем здесь говорится только о пологих склонах - от 1-2 до 10-15 градусов. Это касается давно распахиваемых площадок памятников, где плоскостной смыв может уносить от 5 тонн грунта с одного гектара в год (Романова, 2006, с. 49-51) Следует также отметить, что т. н. «деграда- 
ция» происходила и происходит не только на склонах, но и в оборонительных рвах, а также и насыпях валов, прорезая их, разбивая на отдельные фрагменты (Усков, Водорезов, 2006, с. 113). В некоторых случаях это же может касаться и зафиксированной в наше время незначительной мощности культурных слоев на тех или иных памятниках - аргумент, который иногда приводится в пользу довода о небольшом количестве проживавшего населения на территории отдельных городищ и, как следствие, являющегося показателем малой интенсивности хозяйственной и иной деятельности. Нам думается, что это далеко не всегда соответствует действительности.

Мы выделили лишь общие закономерности определения социального облика булгарских укрепленных поселений, поэтому данное разделение довольно условно. Возможны также и различия между градостроительными процессами домонгольского и золотоордынского периодов.

\section{ЛИТЕРАТУРА}

Археологическая карта Татарской АССР. Западное Закамье. Ч. I / Отв. ред. П.Н. Старостин. Казань: ИЯЛИ КФАН СССР, 1986. 112 с.

Белорыбкин Г.Н. Оборонительные сооружения городищ булгарского времени в Пензенском крае (Сурская группа) // Военно-оборонительное дело домонгольской Булгарии / Отв. ред. А.Х. Халиков. Казань: ИЯЛИ КФАН СССР, 1985. С. 112-120.

Гордеев В.И., Павленко Ю.А. Малый город Поволжья в позднем средневековье / Отв. ред. Ю.А. Зеленев. Йошкар-Ола: Мар. гос. ун-т, 2004. 272 с.

Губайдуллин А.М., Измайлов И.Л. Исследования булгарских городищ в Предволжье // Археологические открытия Урала и Поволжья / Отв. ред. Наговицын Л.А. Ижевск: Удмуртский ин-т истории, языка и литературы УрО АН СССР, 1991. С. 107-109.

Зеленеев Ю.А. Очерки этнокультурной истории Поволжья, XIII-XV вв. Йошкар-Ола: Изд-во МарГУ. 2013. $328 \mathrm{c}$.

Калинин Н.Ф., Халиков А.Х. Итоги археологических работ за 1945-1952 гг. / Труды Казанского филиала Академии наук СССР. Серия исторических наук. Казань: Таткнигоиздат, 1954. 126 с.

Коваль В.Ю. Малые города средневековой Руси: основные отличительные особенности // Труды IV (XX) Всероссийского съезда в Казани Т. III. / Отв. ред. А.Г. Ситдиков, Н.А. Макаров, А.П. Деревянко. Казань: Отечество, 2014. С. 76-79.

Куза А.В. Малые города Древней Руси. М.: Наука, 1989. 168 с.

Плужников В.И. Термины российского архитектурного наследия. Словарь-глоссарий. М.: Искусство, 1995. 160 с.

Романова Е.И. Задачи геоэкологических исследований в изучении культурного слоя на склонах // Склоны на исторических территориях: Материалы VII Международного научно-практического семинара «Комплексное изучение и сохранение исторических территорий» / Под ред. Е.И. Романовой. Рязань: Изд-во Рязанского историко-архитектурного музея-заповедника, 2006. С. 49-52.

Соловьев E.T. Одно из древних булгаро-татарских городищ в Тетюшском уезде // ИОАИЭ. Т. III. Казань: Изд-во Казанского ун-та, 1884. С. 281-284.

Усков В.А., Водорезов А.В. Формирование антропогенных форм рельефа на исторических территориях // Склоны на исторических территориях: Материалы VII Международного научно-практического семинара «Комплексное изучение и сохранение исторических территорий» / Под ред. Е.И. Романовой. Рязань: Изд-во Рязанского историко-архитектурного музея-заповедника, 2006. С. 109-116.

Фахрутдинов Р.Г. Археологические памятники Волжско-Камской Булгарии и ее территория. Казань: Татар. кн. изд-во, 1975. 220 с.

Фахрутдинов Р.Г. Классификация и топография булгарских городищ // СА. 1990. № 4. С. 68-84.

Халиков А.Х. Татарский народ и его предки. Казань: Татар. кн. изд-во, 1989. 220 с.

Хузин Ф.Ш., Измайлов И.Л. Археологические разведки в Западном Закамье // Археологические открытия Урала и Поволжья / Отв. ред. Л.А. Наговицин. Ижевск: Удмуртский ИИЯЛ УрО АН СССР, 1991. С. 151-153.

Хузин Ф.Ш. Итоги и перспективы изучения болгарского домонгольского города // Археология Волжской Булгарии: проблемы, поиски, решения / Отв. ред. Ф.Ш. Хузин. Казань: ИЯЛИ АНТ, 1993. С. 5-32.

\section{Информация об авторе:}

Губайдуллин Айрат Маратович, доктор исторических наук, главный научный сотрудник, Институт археологии им. А.Х. Халикова АН РТ (г. Казань, Россия); airg_g@mail.ru 


\section{REFERENCES}

Starostin, P. N. (ed.). 1986. Arkheologicheskaia karta Tatarskoi ASSR. Zapadnoe Zakam'e (Archaeological Map of the Tatar ASSR. Western Trans-Kama Region) I. Kazan: Institute of Language, Literature and History, Kazan Branch of the USSR Academy of Sciences (in Russian).

Belorybkin, G. N. 1985. In Khalikov, A. Kh. (ed.). Voenno-oboronitel'noe delo domongol'skoi Bulgarii (Military and Defence Systems in pre-Mongol Volga Bulgaria). Kazan: Institute of Language, Literature, and History, Kazan Branch of the USSR Academy of Sciences, 112-120 (in Russian).

Gordeev, V. I., Pavlenko, Yu. A. 2004. Malyi gorod Povolzh'ia v pozdnem srednevekov'e (Small Town in the Volga Area in the Late Middle Ages). Yoshkar-Ola: Mari State University (in Russian).

Gubaidullin, A. M., Izmailov, I. L. 1989. In Savel'eva, E. A. (ed.). Arkheologicheskie otkrytiia Urala i Povolzh'ia (Archaeological Discoveries in the Urals and Volga Region). Syktyvkar: Komi Scientific Center, Ural Branch of the USSR Academy of Sciences, 107-109 (in Russian).

Zeleneev Yu.A. 2013.Ocherki etnokul'turnoy istorii Povolzh'ya, XIII-XV vv. (Essays on the Ethnocultural History of the Volga Region, $13^{\text {th }}-15^{\text {th }} \mathrm{cc}$.) Yoshkar-Ola: Mari State University (in Russian).

Kalinin, N. F., Khalikov, A. Kh. 1954. Trudy Kazanskogo filiala Akademii nauk SSSR. Seriia istoricheskikh nauk (Proceedings of the Kazan Branch of the USSR Academy of Sciences. Historical Sciences Series). Kazan: "Tatknigoizdat" Publ. (in Russian).

Koval, V. Yu. 2014. In Sitdikov A. G., Makarov N. A., Derevianko A. P. (eds.). Trudy IV (XX) Vserossiiskogo arkheologicheskogo s"ezda $v$ Kazani (Proceedings of the $4^{\text {th }}$ (20th) All-Russia Archaeological Congress in Kazan) III. Kazan: "Otechestvo" Publ., 76-79 (in Russian).

Kuza, A. V. 1989. Malye goroda Drevnei Rusi (Small Towns of Ancient Rus). Moscow: "Nauka" Publ. (in Russian).

Pluzhnikov, V. I. 1995. Terminy rossiiskogo arkhitekturnogo naslediia. Slovar'-glossarii (Terms of Russian Architectural Heritage. Dictionary-glossary). Moscow: "Iskusstvo" Publ. (in Russian).

Romanova, E. I. 2006. In Romanova, E. I. (ed.). Sklony na istoricheskikh territoriiakh (Slopes in Historic Landscapes). Ryazan: Ryazan Historical and Architectural Museum-Reserve Publ., 49-52 (in Russian).

Solov'ev, E. T. 1884. In Izvestiia obshchestva arkheologii, istorii i etnografii pri Kazanskom imperatorskom universitete (Reports of the Society of Archaeology, History and Ethnography Affiliated with Kazan Imperial University) III. Kazan, 281-284 (in Russian).

Uskov, V. A., Vodorezov, A. V. 2006. In Romanova, E. I. (ed.). Sklony na istoricheskikh territoriiakh (Slopes in Historic Landscapes). Ryazan: Ryazan Historical and Architectural Museum-Reserve Publ., 109-116 (in Russian).

Fakhrutdinov, R. G. 1975. Arkheologicheskie pamiatniki Volzhsko-Kamskoi Bulgarii i ee territoriia (Archaeological Sites of Volga-Kama Bulgaria and its Territory). Kazan: "Tatarskoe knizhnoe izdatel'stvo" Publ. (in Russian).

Fakhrutdinov, R. G. 1990. In Sovetskaia Arkheologiia (Soviet Archaeology) (4), 68-84 (in Russian).

Khalikov, A. Kh. 1989. Tatarskii narod i ego predki (The Tatar People and its Ancestors). Kazan: "Tatarskoe knizhnoe izdatel'stvo" Publ. (in Russian).

Khuzin, F. Sh., Izmailov, I. L. 1991. In Nagovitsin, L. A. (ed.). Arkheologicheskie otkrytiia Urala $i$ Povolzh'ia (Archaeological Discoveries in the Urals and Volga Region). Syktyvkar: Komi Scientific Center, Ural Branch of the USSR Academy of Sciences, 151-153 (in Russian).

Khuzin, F. Sh. 1993. In Khuzin, F. Sh. (ed.). Arkheologiia Volzhskoi Bulgarii: problemy, poiski, resheniia (Archaeology of the Volga Bulgaria: Problems, Research, Answers). Kazan: Institute of Language, Literature and History named after G. Ibragimov, Kazan Branch of the USSR Academy of Sciences, 5-32 (in Russian).

\section{About the Author:}

Gubaidullin Airat M. Doctor of Historical Sciences, Institute of Archaeology named after A.Kh. Khalikov, Academy of Sciences of the Republic of Tatarstan. Butlerov St., 30, Kazan, 420012, the Republic of Tatarstan, Russian Federation; airg_g@mail.ru 